Progress in Development Studies 10, 3 (2010) pp. 211-31

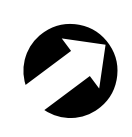

\title{
Integrating reflexivity into livelihoods research
}

\section{Martin Prowse}

Institute of Development Policy and Management (IOB), University of Antwerp, Antwerpen, Belgium

\begin{abstract}
Much development research is not explicit about its methodology or philosophical foundations. Based on the extended case method of Burawoy and the philosophy of critical realism, this article discusses a methodological approach for reflexive livelihoods research that overcomes the unproductive social science dualism of positivism and social constructivism. The approach is linked to a livelihoods framework, and a sequence of research methods that can be iterated in light of research questions.
\end{abstract}

Keywords: methodology, epistemology, ontology, livelihoods, research methods

Stating explicitly how social research is organised, and where in the spectrum of socialscientific standpoints it claims to reside, are fundamental elements of rigorous and ethical research. It can be argued that this is especially the case for development studies compared to other social science disciplines. Not only because of the relative youth of the subject as a distinct (albeit contested) disciplinary area (Kothari, 2005), but also because of the seemingly ever expanding remit of what constitutes 'development' research, and the lack of theoretical depth which this increased width has engendered (Bernstein, 2005).

Instead of engaging with methodological or epistemological debates, much poverty and development research presents a smooth ex post account of research methods (often airbrushing dead ends and false starts). This tendency may be exacerbated by publishing protocols regarding the length, structure, format and style of outputs. While such 'disciplining' serves a purpose (for it contributes to an easily accessible text for the reader to follow), relegating methodology and epistemology entirely to the recycle bin can be detrimental for the research process, and for the relevance of findings.

This article suggests that there are substantial benefits in adhering to a clear methodology and being explicit about a philosophical standpoint when conducting and reporting primary research. Doing so can help to explain how research findings are generated, how robust findings are, and how findings can or cannot be extrapolated.

To be able to make this argument, the article discusses the philosophical underpinnings on which much development research is explicitly or implicitly based. The issue here is 
the relationship between a researcher and the external world (which includes the people who participate in our research). There are two key parts to this question (Danermark et al., 2002; Santos, 2005). First, 'what is the nature and constitution of objects in the external world?' often referred to as ontology. Second, 'how can we as researchers gain knowledge about the external world?' often referred to as epistemology. These metatheoretical questions and predicaments are not subject to definitive closure. The choices that development researchers make regarding their ontological and epistemological position relate, first, to their subjective values, beliefs and worldview (Conticini, 2004; Punch, 1994; Santos, 2005), and second, to practical considerations about the research process and research design.

When attempting to answer these two questions, researchers benefit from considering three core issues. First, that there must be a degree of consistency between ontological beliefs and an epistemological standpoint (Guba and Lincoln, 1994). In other words, our beliefs about the nature of the external world influence how we as researchers can or cannot gain knowledge about it. Second, ontological and epistemological understandings necessarily dictate how data is generated, the attribution of causality, and if findings can be extrapolated (Danermark et al., 2002; Steinmetz, 1998). In other words, our beliefs about the relationship between a researcher and the external world determines what we count as evidence, why we claim to know why change occurs, and to whom and where we can reasonably apply our findings. And third, a methodology must form a web that links the epistemological question (of how we can or cannot gain knowledge about the external world) to the choice of research methods (Guba and Lincoln, 1994). In other words, the research approach and design, and researchers' positionality and stance within it, should connect our beliefs about how we generate data to our selection of research instruments.
This article suggests how these three core considerations can be incorporated in micro-level research concerned with how individuals and households make a living in other words, livelihoods research. It argues that the methodology of Burawoy's extended case method (ECM) and ontological/ epistemological stance of critical realism provides a basis on which to conduct reflexive livelihoods research.

The article contains six sections. As the extended case method is not widely utilised in development studies (despite being applicable and apposite), the first section outlines Burawoy's (1998) methodological approach to ethnographic sociology in some detail. The second section discusses which ontological beliefs and epistemological standpoints might be consistent with such a methodology through discussing the tenets of the most common epistemological standpoints in social science: positivism and social constructivism. As the extended case method is incommensurate with both of these stances, the section suggests that critical realism provides a solid ontological/epistemological basis for reflexive livelihoods research. The third section discusses livelihoods research and frameworks. It sketches out the contemporary origins of livelihoods research, outlines and critiques the (now largely defunct) Sustainable Rural Livelihoods approach, and suggests that Ellis's (2000) rural livelihoods approach provides a good conceptual framework integrating reflexivity into livelihoods research. The fourth section discusses which research methods could inform this livelihoods framework (within the methodological approach of the ECM, and the standpoint of CR). It offers a sequence of research methods that can be iterated in light of research questions, and suggests reasons as to why sequencing quantitative, qualitative and participatory research methods is important. The fifth section summarises the central argument of the article, while the sixth concludes by suggesting that extensive primary fieldwork - required by the

Progress in Development Studies 10, 3 (2010) pp. 211-31 
first two dimensions of the ECM - requires sensitivity, reflexivity, application and longterm dialogue between researchers and social actors.

\section{The extended case method}

The extended case method is an approach to conducting ethnographic sociological research (Burawoy, 1991, 1998, 2000, 2003). At the simplest level, ethnography can be described as the practice of direct observation of social phenomena by an individual participant (see Vidich and Lyman, 2000: 39). A thicker definition of the term is provided by Willis and Trondman:

Ethnography is a family of methods involving direct and sustained social contact with agents, and of richly writing up the encounter, respecting, recording, representing at least partly in its own terms, the irreducibility of human experience. Ethnography is the disciplined and deliberate witness-cum-recording of human events. (Willis and Trondman, 2000: 5)

The ECM is one member of this family of methods, which are widely utilised within social science research. As this particular style of participant observation takes dialogue and reflexivity as its main defining features, we describe the ECM in some detail to illustrate how development researchers can benefit from being aware of their positionality.

The ECM is 'extended' in four dimensions (Burawoy, 1998). Each dimension is guided by a reflexive principle. These reflexive principles minimise the power effects inherent in researching and writing about the social world. The four dimensions, their attendant reflexive principles and the power effects which reflexivity militates against, are now summarised in turn.

The first dimension is the movement of the observer to participant, with the researcher leaving their own social world and entering the social world of the participants. In contrast to positivist research that attempts to insulate the effects of the researcher's intervention on the social context, the ECM recognises that all interventions create disturbances. Indeed, the ECM suggests that being sensitive and reflexive about disturbances can be the basis for understanding some aspects of participants' social context. In other words, 'interventions create perturbations that are not noise to be expurgated but music to be appreciated, transmitting the hidden secrets of the participants' world' (Burawoy, 1998: 14). This type of reflexive research recognises the power relations that are inherent within research relationships (and indeed within all social fields). These power relations are unavoidable, cannot be dissolved and limit our understanding of the social world.

The second dimension of the ECM is that participant observation is extended through time and space - it is only through longitudinal immersion in a social world that ethnographers are able to link scenarios and circumstances, compare them with theory and build up a picture of social processes. However, through aggregating social situations, and integrating multiple observations into social processes, researchers unavoidably make choices, thereby silencing particular experiences and voices. The ECM necessitates an awareness of the power of the researcher to privilege certain voices and exclude others.

The third dimension is to extend out from micro-processes to macro-forces. In a similar fashion to Murray (2002) and Long (2001), this necessitates linking observations and social processes to their historical development, and to both macro-societal and international forces. This does not just involve showing the means through which structuration occurs (Giddens, 1984), but necessitates an understanding of how the global influences the local. The inherent danger with linking microlevel processes with macro-level forces is what Burawoy calls 'objectification' - giving macro forces primacy in determining social actions and practices (Long, 2001: 13). This is tempered by the explicit recognition of the capacity and innovation of social actors. 
The fourth dimension is extending theory. Taking the perspective that theory never just emerges from data (Glaser and Strauss, 1967), the ECM looks not to confirm theory, but to contest it. Throughout the research process data and theory are juxtaposed, with tentative predictions investigated and assessed, and anomalies and unexpected results helping to reconstruct theory. This leads towards an evolving set of research hypotheses with appropriate research tools deployed to investigate a particular phenomenon. Through an iterative dialogue, and the eventual presentation of research findings to research participants, data and theory are eventually brought together. However, in attempting to make the world comprehensible by reducing complexity to categories, there is a danger that data is shoehorned into a theory, or theory is altered needlessly to incorporate superficial data. The two-way process of reconstructing theory necessitates that uncertain data and speculative theoretical postulations end up on the cutting room floor (as is good practice in much social science research).

These are the fundamental tenets of the ECM. It is an unusual approach to ethnography by current sociological and anthropological standards due to its approach to 'extroversion': in other words, engagement with macro and global forces instead of the intensive study of a small locality (Burawoy, 1991: 6; Burawoy, 2000). The ECM's focus on the role of global forces stems from early ethnographic approaches in sociology (Hammersley, 2004; Thomas and Znaniecki, 1927), and later ethnographic approaches from the Manchester school of anthropology (Gluckman, 1941: Wilson, 1941). In addition to 'extroversion,' and providing its name, the Manchester school made five further contributions to the development of the ECM.

First, that an incisive method of analysing social process is to focus on conflict and social drama (Turner, 1957). Second, that to highlight the complexity of the social world, the ethnographic account should focus on a small number of (often related) individuals or groups (Long, 1968). Third, that a focus on discrepant cases can give a clear understanding of social process -in other words, exceptions often prove the rule (van Velsen, 1964; van Velsen, 1967). Fourth, that focusing on social process necessitates the study of practices as well as norms and discourse (ibid.). And fifth, that both quantitative and qualitative research tools can be used within an ethnographic research project.

The Manchester School provided important underpinnings for the ECM, which appears to be a useful methodology for micro-level research in development studies. But on what ontological and epistemological position can this methodology be based? We discuss this question through outlining two common epistemological standpoints in the social sciences: positivism and social constructivism. We then summarise a further philosophical position: critical realism.

\section{Positivism, social constructivism and critical realism}

\section{Positivism}

Positivism seeks to understand the social world by uncovering universal laws through the measurement of the 'constant conjunction of events' between two or more phenomena (Steinmetz, 1998). These universal laws are empirical generalisations which are seen to be (mainly) independent of time/space and are neutral and value-free (Steinmetz, 1998). Positivists usually discover empirical generalisations through setting up and testing hypotheses in a deductive manner, with nonfalsified hypotheses being extrapolated to a wider range of cases (Danermark et al., 2002; Popper, 1992). Non-falsified hypotheses are accepted and extrapolated because positivists understand the social world as a closed system (Steinmetz and Chae, 2002). In this

Progress in Development Studies 10, 3 (2010) pp. 211-31 
respect, positivism is a form of naturalism which believes in the unity of the natural and social sciences (Bhaskar, 1989), and hence attempts to replicate the requirements of physical science, such as prediction, closed experimentation and the separation of research findings from interpretation (Steinmetz and Chae, 2002).

Positivism's hypothetico-deductive explanatory model relies on Humes' model of causation where 'regularity conjunctions are both necessary and sufficient for attributions of causality' (Baert, 1998: 192). For positivists, the observation that two theoretically connected variables are strongly correlated is often understood to signify a causal relationship (Danermark et al., 2002; Green and Hulme, 2005). However, critics argue that positivists' explanations often just observe statistical relations that do not refer sufficiently to generative causal mechanisms (Baert, 1998; Danermark et al., 2002), and that the extent to which positivism moves seamlessly from expost explanation to ex ante prediction is contentious (Baert, 1998).

Positivism is (usually) linked to empiricist ontology. This states that nothing exists in the external world outside of observable phenomena and rejects the invocation of theoretical, abstract and unobservable entities' (Steinmetz, 2004: 357). For empiricists, causality occurs at the same level at which their effects are felt, the very same level that individuals can access and gain knowledge about (Steinmetz, 2004). Empiricists also believe that social mechanisms exist 'independently of the agents' conceptions of what they are doing in their activity' (Bhaskar, 1979: 48), and thus agents' interpretations are not of importance to social research (Steinmetz, 2004).

Burawoy (1998) outlines three main context effects that make positivism incommensurate with the ECM. First, positivist research marginalises interview effects - in other words, researchers' socio-biographical characteristics do not influence the generation of data (due to an assumed objectivity). Second, positivist research ignores respondent effects this is where the message received by the respondent is different from the message intended by the researcher. Both of these contextual effects relate to the same key point: people do not act like molecules but interpret the social world and act accordingly. Third, positivists' assumed closed system often ignores field effects: the political, social and economic currents that permeate all social fields. An example from the physical world that of a falling leaf - helps to elucidate this point (Baert, 1998). If the physical world were a closed system then, according to the law of gravity, one would expect a leaf to fall from a tree in a straight line. Instead, falling leaves are subject to a wide variety of forces, and their trajectories are highly varied and difficult to predict. This is not to say that the law of gravity doesn't hold good. Of course it does. But, even in the physical sciences, closed systems are unusual. Therefore, in the social world, which is certainly an open rather than a closed system, the physical science method of falsification and extrapolation may not be as accurate as we would like (in other words, isolating the influence of one factor from other factors is extremely hard, and is hard to achieve with main focus on bivariate relationships). We've seen that the ECM is incommensurate with positivism. However, the ECM also appears incompatible with the other main standpoint in the social sciences social constructivism.

\section{Social constructivism}

Social constructivism is related to, but distinct from, the much older interpretive tradition in sociology. Based on the neo-Kantian distinction between the study of the social world and the natural world because the former is 'inherently meaningful' (Schwandt, 2000: 191), interpretive researchers are concerned with understanding the meanings that individuals ascribe to their surroundings, actions and practices. This is 
because individuals' subjectivities stimulate and are constitutive of conduct and action (Baert, 1998). Interpretivist researchers are sometimes able to gain access to the realm of both discursive and tacit knowledge through qualitative methods, especially participant observation (where gaining understanding of one action is often predicated on a wider understanding of the full range of actions see Schwandt, 2000).

Social constructivism is distinct from this interpretivist tradition, and takes exception to the way 'the interpreter objectifies (that is, stands over and against) that which is to be interpreted' (Schwandt, 2000: 194). Social constructivists posit that all types of knowledge are constructed within the cognitive framework and a priori theoretical concepts of an individual - therefore all understandings of the external world are not reflections of it, but are solely subjective interpretations (Schwandt, 2000). In this respect, social constructivists deny the possibility of accessing objects in the external world (Steinmetz, 1998). They tend to be sceptical of any truth claims, and doubt the validity of any representation of the external world. Moreover, they are often 'judgemental relativists' and do not offer any criteria by which different interpretations can be appraised. From this perspective, all knowledge is predicated on the values, ideas and judgements of the individual, and is locally and contextually defined (Danermark et al., 2002). In addition, the aggregation of values, ideas and beliefs, and their enactment in actions and conduct, lead to the creation of 'real' social processes - thereby discourses are not only the myths that we like to live by, but are key structuring principles in society (Santos, 2005).

Just as with positivism, there are considerable tensions between this standpoint and the ECM. First, 'judgemental relativism' is a position that is incompatible with research that engages with macro forces (be they social - such as discrimination - or economic, such as industrial restructuring, tax regimes or welfare provision), and aims to contest and extend social science theory (not to mention engagement with policy or practice). And second, some social constructivists believe in the impossibility of social and cultural translation (Steinmetz, 2004). Based on the linguistics of Saussure, such researchers posit that as soon as one leaves one's own social community, researchers are unable to 'translate' social actions and conduct. In combination with unequal power relationships between researchers and respondents, such translation difficulties contribute to social researchers imposing their own distinctions, understandings and beliefs on the social context, thereby reducing cultures and social practices to their own metric (Steinmetz, 2004). The implication of this 'lost in translation' argument is that social research outside of one's own community is untenable - a position at odds with the first and second dimensions of the ECM.

Many argue that the axioms which underpin these two philosophical standpoints-positivism and social constructivism - render them mutually exclusive (Denzin and Lincoln, 2000). Danermarket al. (2002) refer to this dichotomy in the social sciences as the either/or approach. In contrast, critical realism is an attempt at a both/and approach to social research, and as we will see, is one that is much more consistent with the tenets of the ECM.

\section{Critical realism}

Critical realism (CR) argues that social science should be able to make generalised claims (thus not falling into the "judgemental relativism' of social constructivism), but that the subjectivities of individuals and the meanings imbued within action are central to understanding the external world (thus rejecting the 'concept independence' of positivism). It achieves this apparent paradox by taking an optimistic and pragmatic philosophical position. Instead of focussing on the epistemological question of 'how can we gain knowledge about the external world?' critical realists focus on

Progress in Development Studies 10, 3 (2010) pp. 211-31 
a stratified and complex view of ontology (Steinmetz, 2004), and ask 'what properties do societies and people possess that might make them possible objects for knowledge?' (Bhaskar, 1978: 13).

CR thus outlines three ontological domains - the empirical, the actual and the real (Bhaskar, 1978; Danermark et al., 2002). The empirical domain is that which human experience is limited to, and in which our research data is generated. Our experience of this domain is necessarily filtered by our sociobiographical characteristics and mediated by our conceptual beliefs. The second ontological domain is the actual. This includes the empirical domain, but also includes those events that occur in the world but which nobody experiences. For example, if a tree falls in a forest but is not seen by someone, it occurs in the actual domain. The third ontological domain is the real. This includes both the empirical and the actual, and generative causal mechanisms that create concrete events in the external world. Danermark et al. (2002) explain that when such 'mechanisms produce a factual event, it comes under the domain of the actual, whether we observe it or not. When such an event is experienced, it becomes an empirical fact' (Danermark et al., 2002: 199). CR seeks explanation through analysing causal mechanisms via the effects they create in the empirical domain. But what methods and conceptual tools enable critical realists to theorise about casual mechanisms?

Critical realists argue that causal mechanisms can be understood through conceptual abstraction - isolating certain aspects of a phenomenon from wider forces that are acting on it. Abstraction is achieved through the repetitive iteration of theory with data generated in the empirical domain, leading to the refinement of hypotheses and the restructuring of theory. In addition to deduction (inferring particular instances from a general law) and induction (the inference of a general law from particular instances), such abstraction can be facilitated through two particular kinds of inference - retroduction and abduction. Retroduction involves abstracting from the empirical domain to the actual and real domains through theorising about what are the prerequisites for a phenomenon to exist (Danermark et al., 2002: 96). Two practices are central to retroduction - counterfactual thinking, and the study of extreme cases. Abduction involves drawing upon analogies and metaphors (Baert, 1998: 193), and often relies on the importation of concepts from different academic disciplines.

While not a panacea for social researchers, its attempt 'to combine and reconcile ontological realism, epistemological relativism and judgemental rationality' (Archer et al., 1998: xi), suggests that CR may provide social researchers with a philosophical route out of the staid and unproductive dualism of positivism and social constructivism. That is not to say, of course, that CR doesn't suffer from shortcomings. Here, we outline three. First, while CR is based on strong philosophical underpinnings, it is relatively silent in terms of methodology (a gap which the ECM can fill). Second, while critical realists advocate 'critical methodological pluralism' (Olsen and Morgan, 2005), the approach appears to lack a detailed discussion of how research methods can be combined and sequenced (we discuss this in section four). And third, Bhaskar's 'transcendental realism,' on which critical realism is based, is a form of naturalism that believes in the unity of the physical and natural sciences. The inflection of naturalism, the holistic approach to inference (where deduction is not rejected outright) and use of quantitative research tools (such as surveys), leads critics (including many social constructivists) to reject critical realism as a form of positivism (Denzin, 2004; Denzin and Lincoln, 2000).

More importantly for the purposes of this article, there is a great degree of consistency between CR and the ECM. Here we outline ten similarities: $(i)$ ontological realism - that it is possible to gain knowledge of the external 
world; (ii) epistemological relativism - that all knowledge is predicated on a priori theoretical sensitisation, but as knowledge is theorydependent not theory-determined, empirical work is valid, not as a representation of the truth but to improve theory; (iii) judgemental rationalism - that logic dictates the criteria by which theories can be judged, and how research can inform practice; (iv) while acknowledging the centrality of agency, the primary focus is on highlighting societal structures; (v) that causal mechanisms are not laws that can be uncritically extrapolated, but should be seen as 'tendencies' which are time and space specific; ( $v i)$ that generative causal mechanisms are most obvious during moments of conflict and drama, and within discrepant cases; (vii) that theory and data should be iterated repeatedly to redefine research questions and hypotheses; (viii) that dialogue between researchers and participants, and reflexivity by researchers, are key defining principles, and that the power relations inherent within social research must be recognised; (ix) that within empirical work, the nature of the subject determines the methods; and lastly $(x)$, the need to focus on practices as well as meanings, norms and values.

So far we have seen that the ECM provides a useful methodology for micro-level research in development studies, and that this methodology appears consistent with the ontological/epistemological stance of critical realism. But, what body of literature, and conceptual framework, can benefit from this methodology and philosophical position? The following section suggests that the ECM and critical realism provides a good foundation for integrating reflexivity in livelihoods research.

\section{Livelihoods research and frameworks}

Livelihoods research is a relatively recent approach to development-related research (Murray, 2000). It is most frequently equated with the Department for International Development's (DfID) 'Sustainable Rural Livelihoods' (SRL) approach (Ashley and Carney, 1999;
Carney, 1999; DflD, 2000: 3), which defines a livelihood as comprising 'the capabilities, assets (including both material and social resources) and activities required for a means of living.' The SRL approach consists of five elements (as illustrated in the once ubiquitous SRL framework): a vulnerability context; an asset pentagon; transforming structures and processes; livelihood strategies and livelihood outcomes (hopefully, increased well-being, more income, reduced vulnerability, improved food security and a more sustainable use of the natural resource base) (ibid.). At the time when DfID supported the utilisation and expansion of the SRL approach (see Clark and Carney, 2008), advocates argued that the added value of the approach was the realisation of crosssectoral analysis, the focus on people's strengths, and the link between macro-, mesoand micro-levels of analysis (Carney, 1999). A further, and important, contribution was increasing the recognition of livelihood diversity in developing countries (Ellis, 2000; Haggblade et al., 2007; Reardon, 1997).

\section{Origins of livelihoods research}

Until the early 1970s, it was widely assumed that individuals in developing countries not employed in the advanced capitalist sector were farmers or fishermen languishing in a backward, non-capitalist sector. This view of the economy was shared by both modernisation and marxist theories of development. The modernisation theorists' perspective (Huntingdon, 1968; Parsons, 1964) stemmed in part from the Lewis model of structural change, which saw the reallocation of labour from the 'backward' to the 'modern' sector as the route to employment creation and economic growth. Separating the economy into discrete segments obfuscated the connections between rural and urban spheres, and the livelihood strategies between these areas.

From an orthodox Marxist perspective (relatively popular at the time), rural dwellers were seen as leading a primarily agrarian

Progress in Development Studies 10, 3 (2010) pp. 211-31 
existence, and peasants would be subject to the inexorable process of proletarianisation. Successful peasant production or social movements were seen as obstacles to the formation of this 'class' (O'Laughlin, 2002), and informal ways of making a living were seen as a device for depressing formal wages (Allen, 1998: Francis, 2000). Such a teleological understanding of social change 'robbed African peasants and workers of agency, their distinctive histories and their cultural identity' (O'Laughlin, 2002: 513).

However, these dualistic and teleological theories of economic activity and social change had little resemblance to the ways many people were making a living in developing countries. For example, Hart's (1973) analysis of urban migrants in Accra showed that instead of being underemployed, members of the urban sub-proletariat (as they were described then) managed multiple economic activities and income streams not recognised by the state (Allen, 1998: 357; Harriss, 2002). Hart termed this the 'informal sector,' a term quickly picked up by the International Labour Organisation (ILO) (and which is now part of the development lexicon). Hart's (1973) work shows the ability of micro-level research to understand ways of making a living not acknowledged by mainstream development theory, and can be seen as an early example of livelihoods research (Francis, 2000). However, a more common starting point for the development of a livelihoods perspective was the growing interest in a multi-dimensional understanding of poverty in the 1990s.

The development of the SRL approach dovetailed with, and benefited from, the 'New Poverty Agenda,' which recognised the deficiencies of a solely income-based measurement of poverty. Using the experience of rapid East Asian industrialisation, and echoing earlier 'Basic Needs' approaches to development (Stewart, 1985; Streeten et al., 1982), the 1990s saw an increasing acceptance of health and education within a multi-dimensional view of poverty (World Bank, 2000). It can be argued that four further influences from the 1980s fed into this expanded conception of poverty (Maxwell, 1999): Sen's work on entitlements, capabilities and functionings (Dreze and Sen, 1991; Sen, 1981); Chambers' (1989) incorporation of isolation, powerlessness and vulnerability into his conception of poverty; the Brundtland Commission's report on 'sustainable development' (Redclift, 1987); and a renewed interest in vulnerability and coping strategies (de Waal, 1989). It can be argued that Chambers and Conway (1992) brought these disparate intellectual trends together, and proposed the Sustainable Rural Livelihoods (SRL) framework, later expanded by DfID (2000) and others.

\section{Shortcomings of the SRL approach}

Needless to say, the SRL approach suffered from a variety of shortcomings. For example, five broad criticisms have been levelled at the terminology and structure of the framework. First, that the SRL approach has an undertheorised and implicitly unitary model of the household, instead of utilising a model of cooperative conflict (Rakodi, 2002). Second, the SRL approach has an overly optimistic assumption that individuals and households are able to strategise as opposed to cope. In this respect, the term 'livelihood strategy' overemphasises the ability of individuals/households to choose and select activities to make a living (dependent on their endowments and capabilities) and negates the significance of the opportunities available to the individual/ household (Allen, 1998; Rakodi, 2002; Toner, 2003; Wood and Solway, 2000). Third, that the SRL approach contains an underemphasised and limited understanding of a 'vulnerability' context (Moser, 1998; Murray, 2000; Wood and Solway, 2000). Fourth, that it is hard to unpack the policies, institutions and process (PIP) box (Clark and Carney, 2008). And finally, that the term 'sustainable' is too ambiguous (Murray, 2000; Murray, 2002) and should be divided into livelihood 'security' and livelihood 'sustainability' (Rakodi, 2002). 
Three further criticisms focused on the conceptualisation of assets. First, that the assets in the SRL approach are not directly comparable (Beall, 2002; Maqueen, 2001; Pretty, 1999; Toner, 2003). Second, that the term social capital is of no analytical value as it is conceptualised in the SRL approach, and needs to be comprehensively disaggregated (Harriss and de Renzio, 1997; Woolcock, 2001). Third, that the term social capital is too optimistic as it ignores processes of dependency (patron-client relations) and social exclusion (Beall, 2002; Thin, 2000; Wood, 2003).

Despite criticisms, the SRL framework was used and expanded by NGOs (such as Oxfam, CARE and Save the Children), research centres (such as the Institute of Development Studies, and the Overseas Development Institute), and donor agencies (for example, the Food and Agricultural Organisation, the International Fund for Agricultural Development and the Swedish International Development Cooperation Agency), and entered mainstream UK development discourse (Ashley and Carney, 1999). However, applying the frameworks proved difficult. Donors and NGOs found it extremely difficult to operationalise, and attempts to apply the entire framework overwhelmed staff, leading to concerns that livelihoods analysis became an end in itself, without contributing to evidence-based policy (DflD, 2001; Hussein, 2002).

Moreover, support from DflD waned. Clark and Carney (2008) outline how both internal factors - such as SRL's close association with agriculture and rural development, and a lack of dialogue with the key departments, notably, health, education and private sector development - and external trends (such as the shift away from project-based lending towards budget support, good governance and further process-based issues) contributed to the marginalisation of the approach. In recent years, and partly due to the curtailment of DfID support, the SRL approach has slipped off the development radar. Livelihoods frameworks are now seen as being unwieldy and unfashionable. But it is important they are not discarded, for, as we have seen in the case of Hart, livelihoods research can highlight ways of making a living not appreciated in mainstream theory, or in policy circles. For example, if we consider the impact that current global forces have on individuals and households in developing countries - for example, globalisation and migration, the challenges (and opportunities) of climate change, food price volatility or the impact of the current recession - it can be argued that livelihoods research remains an important approach to understanding how poor households in low-income countries combine activities and straddle spaces. However, the conventional SRL approach does not appear to be best suited to this role. A more promising approach (for rural locations, at least), and the one which is more consistent with the ECM (and, in turn, the standpoint of CR), is Ellis' (2000) rural livelihoods framework.'

Ellis (2000) contends that a livelihood comprises 'the assets (natural, physical, human, financial and social capital), the activities, and the access to these (mediated by institutions and social relations) that together determine the living gained by the individual or household' (p.10). Ellis divides the study of livelihoods into six related components, and starts with an individual's or household's assets. These contribute to livelihood strategies, within a vulnerability context of trends and shocks, and through the mediating processes of social relations, institutions and organisations (see Figure 1).

There are three important differences with DfID's SRL framework which make Ellis's (2000) framework much closer to the ECM and CR. First, Ellis emphasises the importance of socio-biographical characteristics - such as gender, class, age and ethnicity - to a greater extent than the SRL does within the PIP box (important considering the four dimensions and reflexive principles of the ECM). Second, Ellis focuses on 'markets in practice,' 


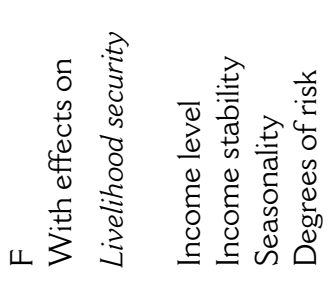

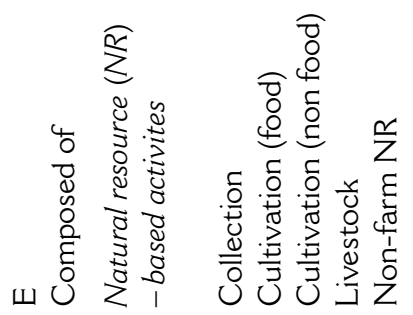
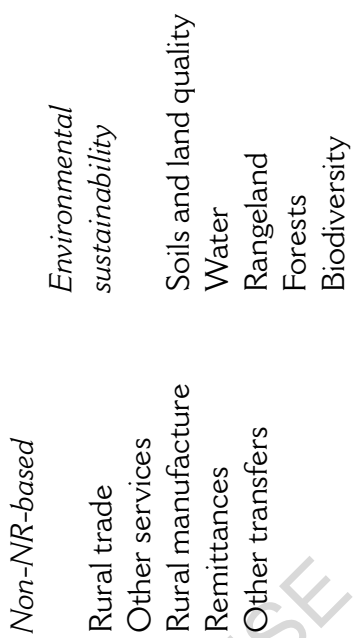<smiles>C[13CH][13CH]=[13CH]</smiles>
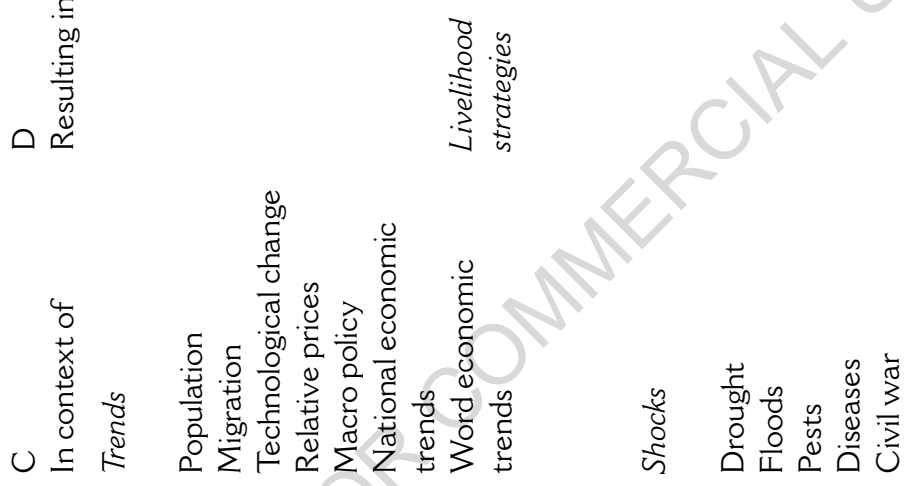

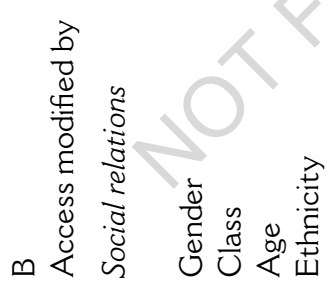
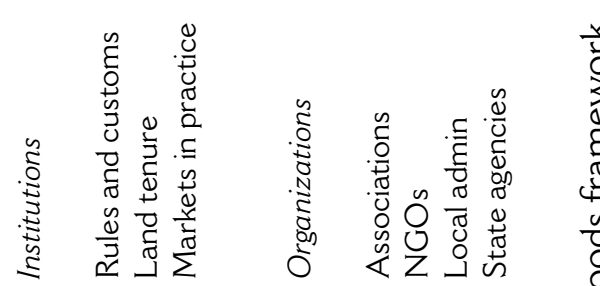

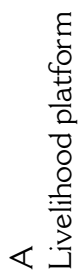
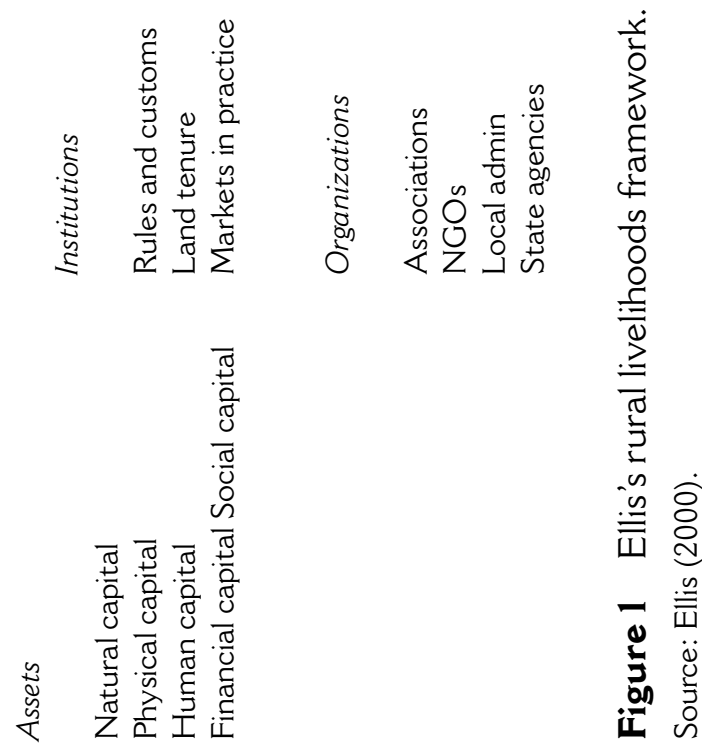
as opposed to an assumed scenario of market clearing at optimally efficient prices and contract enforcement. This is significant for it suggests that the structure and social organisation of markets must be researched (for example, through value chain analysis) and not assumed. And third, Ellis (2000) differentiates between livelihood security and environmental sustainability (thus overcoming a key criticism of the SRL approach) (Murray, 2002). This is not to say, of course, that Ellis' approach could not be improved. For example, the separation of strategies into natural-resource-based strategies and non-natural-resource-based strategies (Ellis, 2000: 40-41) does not appear to be particularly helpful. And while Ellis is cautious about applying livelihood typologies to this part of the framework - such as Scoones' (1998) suggestion to differentiate strategies into (agricultural) intensification/extensification, diversification and migration - grouping strategies together makes intuitive sense and aids comparison. ${ }^{2}$ Overall, though, Ellis (2000) framework appears very suitable for reflexive livelihoods research.

\section{Research methods}

We have seen that both the ECM and CR advocate a combination of quantitative and qualitative research methods. Effective and rigorous livelihoods research also depends upon a sequence and combination of quantitative and qualitative tools (as well as an explicit and sustained analytical tension between macro-, meso- and micro-levels of analysis, which in itself requires a mixed methods approach) (Murray, 2002). But which methods are most suited for reflexive livelihoods research? A good starting point in this discussion is that social research methods sit at some point along five broad continua (Kanbur, 2001):

1. Type of information on population: non-numerical to numerical.

2. Type of population coverage: specific to general.
3. Type of population involvement: active to passive.

4. Type of inference methodology: inductive to deductive.

5. Type of value framework: multidimensional value vs. money-metric value.

In the majority of cases, quantitative methods - such as surveys - can be found at one end of the continuum (for example, numerical information, specific coverage, passive involvement, deductive methodology and unidimensional value framework). And frequently, qualitative studies are found towards the other extreme.

In this respect, different types of research methods provide different types of data, and are therefore good at answering particular kinds of research questions. For example, numerical methods are good at answering 'what', 'where' and 'who' questions, and are good at capturing states or conditions (Ellis, 2000), while nonnumerical methods are good at answering 'how' and 'why' questions (Woodhouse, 1998), and are thus good at capturing processes (Murray, 2002). However, as the contextual benefits of qualitative research strive towards depth of understanding, this is usually only within a small locality. One of the major strengths of quantitative methods is the breadth of coverage (Chambers, 2001).

The challenge, therefore, is to integrate quantitative and qualitative research methods in a way which captures depth of understanding and breadth of coverage, while being rigorous and reliable and adhering to the reflexive principles outlined in the ECM. Booth's (2001) and Rao's (2001) contributions are helpful in this respect as they highlight different methods of integrating survey-based and contextual research methods, and suggest four combinations:

1. Parallel-where the research methods are conducted separately and both

Progress in Development Studies 10, 3 (2010) pp. 211-31 
inform the findings and outputs of the research.

2. Linkage - where contextual investigations, such as qualitative interviews, are a sub-component of a sample survey, with the interviews fitted to survey sampling frames.

3. Convergence-where contextual methods take on properties normally associated with surveys (for example, random sampling).

4. Triangulation - Where different data sources, both between and within the two main methodological traditions, are sequenced and combined within the research design. There are two versions:

(a) Classical - where contextual methods are used to generate a hypothesis which is then tested rigorously with quantitative statistical analysis; (b) Bayesian - methods which are integrated in an iterative and dialogic fashion.

Following from the tenets of the ECM and critical realism described above, the combination of research methods most suited to reflexive livelihoods research is the Bayesian approach to the triangulation of quantitative and qualitative methods.

Table 1 shows one sequence of research methods that utilises this Bayesian approach to triangulation. While precise instruments are suggested under 'style of research' and 'type of research method/analysis' columns, these are just indicative. The more important issue the table tries to convey is how the 'categories' of qualitative, quantitative and participatory methods could be sequenced (although the precise sequence of methods should be defined by the nature of the research questions, not a predefined schedule). The matrix also suggests where each of the categories lies on the five continua outlined above.

Table 1 suggests that a literature review and analysis of secondary datasets should precede primary data generation. During primary research, Table 1 suggests two qualitative methods that are suitable at the meso-level ethnography and qualitative institutional research. Most importantly for a reflexive livelihoods approach, Table 1 suggests a possible sequence of research methods at the micro-level: participatory - qualitative quantitative - qualitative - participatory.

There are numerous reasons why such a sequence of research methods, at both levels, is important. Here we outline eight reasons. First, a comprehensive literature review and analysis of secondary data sources prior to fieldwork allows the research to be conducted in a suitable location for the phenomenon under study (for example, see the use of gender ratios from census data by Andersson, 2001 and 2006, for studies on migration, or the use of market data by Prowse, 2009, for the study of export crop production). Moreover, if desired, secondary datasets can provide a sampling frame from which a representative sample can be drawn.

Second, substantial qualitative institutional research should be completed prior to conducting research at the micro-level. Not only does this provide further sources of secondary data (documents or datasets), but it can also provide both the diction and discourse utilised by individuals involved in a sector and a summary of current events. Why is this so important? Asking respondents about how they make a living without having a clear idea about language and current affairs may decrease the likelihood of establishing a good rapport with respondents (in other words, they may doubt that you know your subject well enough to offer you their time) and may limit their participation in future research methods (or reduce the accuracy of their responses).

Third, the use of substantial participatory and qualitative methods prior to the construction and implementation of a quantitative 


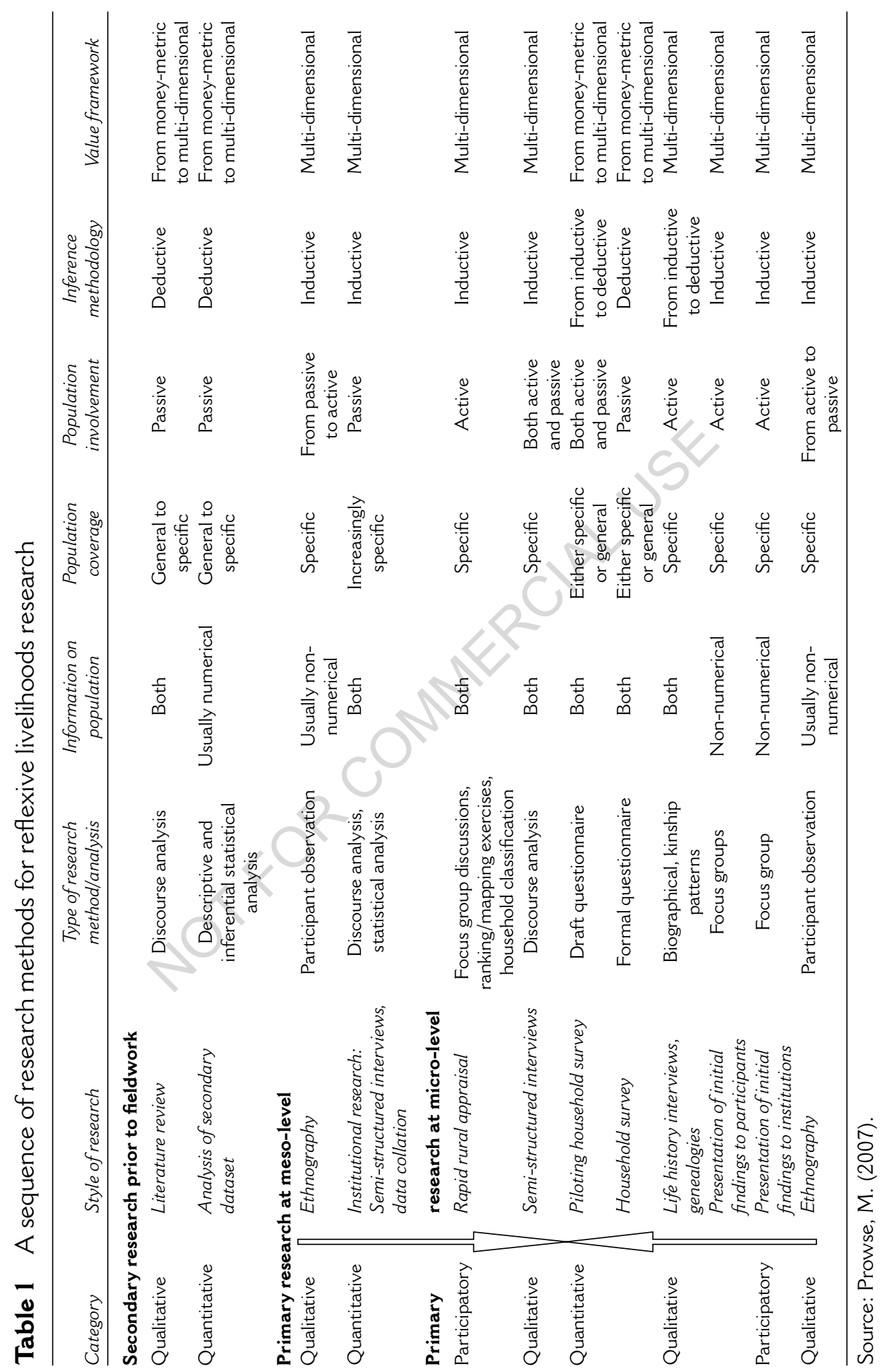


instrument (typically, a survey) helps to ensure inclusion of questions regarding significant local practices and phenomena (although these methods do not obviate the need for the rigorous piloting of a survey instrument). Moreover, early participatory and qualitative methods serve further purposes: on the one hand, they help to generate a rapport with respondents who become familiar with researchers milling around a village or community; on the other hand, they provide important contextual data (on local politics, practices, institutions and kinship patterns).

Fourth, using a quantitative instrument, such as a survey, is a vital tool in helping to answer and quantify 'what,' 'where' and 'who' questions. Fifth, as Murray (2002: 489) outlines, as much livelihoods research takes a circumspective approach (in other words, to 'look around' at one point in time), it is important to complement this with a retrospective approach (to look at change through time). While utilising or constructing panel data (which reports on the same individuals or households at different points in time) may be optimal, in many cases this may not be possible given research constraints. In such cases, life history interviews offer an alternative which allows researchers to reconstruct the past (Davis, 2006; Francis, 2002; Miller, 2000; Murray, 2000).

Sixth, preliminary analysis of survey data should guide further qualitative and participatory methods. For example, the selection of individuals for life history interviews (which may well be extreme cases) or the creation of wealth ranks to suggest informants for further focus group discussions or semi-structured interviews.

Seventh, the presentation of preliminary findings, both quantitative and qualitative, to micro-level participants in the form of feedback focus groups acts as a way of investigating tensions between public discourses and private responses. It can also be seen as a way of corroborating or contesting initial interpretations of the data at hand. Needless to say, sensitive data and issues need to be excluded or broached carefully, (and when this principle is adhered to, such focus groups form part of the ethics of research). The presentation of initial findings to institutions can also provide extremely useful feedback, in particular through comparing how theory and development policy understand the phenomena under study, compared to the public and private responses of social actors.

And last but certainly not the least, that all micro-level research methods are complemented by the observation of, and participation in, social practices, whether in the area of fieldwork, or elsewhere (Murray, 2002). Data from participant observation can provide important insights and direction for more formal research methods.

Underpinning these research methods should be a methodological commitment to the reconstruction of the key research hypotheses in light of the discrepancies and tensions between different research methods. On the one hand, this means contrasting formal public statements and informal private beliefs (Rao, 2001); on the other hand, it means investigating tensions between what individuals say they do and their actual practices (van Velsen, 1967). It may be the case that the most interesting avenues for research stem from apparent contradictions between sources of data. So, it is through the triangulation of participatory, quantitative and qualitative empirical findings that reflexive livelihoods research is able to refine the questions under study, and deploy the most appropriate research tools to further investigate the questions in hand.

In contrast to the rigidities imposed by single discipline studies, in which the depth of analysis and introspection can lead to a loss of clarity and applicability (Hulme and Toye, 2006), development studies has a comparative advantage in cross-disciplinary research. 
For example, Harriss (2002) highlights how seminal contributions - such as Ferguson (1990) and Fairhead and Leach (1996) - take such a perspective. As should be clear by now, reflexive livelihoods research also takes such a cross-disciplinary perspective. However, in seeking to integrate the insights from different disciplines, and trying to steer a mid-path between positivism and social constructivism, the approach runs the risk of lacking analytical depth. Whether this is the case or not may depend on the theoretical level the research engages with. In other words, the approach outlined in this article appears more suited to testing and reconstructing middle range theory (which summarises the insights that livelihoods frameworks can provide) than attempts at all-encompassing theoretical propositions (Merton, 1967; Pawson, 2009).

\section{Summary}

This article suggests that there are substantial benefits in adhering to a clear and explicit methodology and philosophical position when conducting and reporting primary research. For example, claiming an empiricist ontological position and a positivist epistemology help to explicate a methodological choice that replicates the requirements of physical science.

A clear illustration comes from recent interest in experimental research designs within development research (Duflo and Banerjee, 2008; Ravallion, 2009; Rodrik, 2009; Woolcock, 2009). Here, to ensure a rigorous research approach and design, researchers must ensure both internal validity (for example, prevent merging of treatment and control groups, and limit spillover effects between treatment and control groups) and external validity criteria (such as trying to ensure that if the intervention is scaled up, an implementing institution will act in a similar manner as in a pilot, and that the evaluation itself doesn't cause the treatment and/or control groups to change behaviour) so that the research does not contravene the epistemological and ontological beliefs on which the design is (implicitly) based.

On the other hand, being explicit about a relativist ontological/epistemological position, as social constructivists tend to, helps to explain the methodological choice of the analysis of text, discourse and language, and the use of personal narratives and testimonies, supplemented, perhaps, with some form of (possible covert) observation (as, from this perspective, the ripples caused by formal research tools are often seen to be large enough to undermine the validity of the data they seek to generate).

The position this article proposes - a philosophical stance of critical realism, tied to the methodology of the extended case method and the sequencing of multiple research methods - is one approach to integrating reflexivity into livelihoods research. This is not to say, of course, that such a position is the only way of overcoming the staid dualism of positivism and social constructivism in the social sciences. The mid-ground this article attempts to tread also includes postpositivist and interpretivist positions not discussed here. Comparing such philosophical standpoints, and the methodologies, methods and conceptual frameworks they use, might provide development researchers with firmer foundations for their research.

\section{Conclusion}

As is evident from the first two dimensions of the ECM - the movement of the observer to participant, and that participant observation is extended through time and space - this article advocates substantial primary fieldwork. Within some of the social sciences (especially geography and anthropology) fieldwork used to be seen as a rite of passage - the process through which individuals pass to become part of the discipline. This led to remote and rural locations being seen as more 'real' fieldwork

Progress in Development Studies 10, 3 (2010) pp. 211-31 
locations (Ferguson and Gupta, 1997). In this respect the 'fieldwork' tradition in these two disciplines has historically been imbued with 'Victorian-era expectations that personal growth (of implicitly masculine sort) could be affected through pilgrimages to unfamiliar places' (Kuclick quoted in Ferguson and Gupta, 1997: 48). While there is no doubt that fieldwork is a time of personal growth, it is not necessarily of the masculine explorer variety. As the ECM shows, fieldwork is a process which requires sensitivity, reflexivity, application and on ongoing dialogue between the researcher and social actors.

Being sensitive to the ripples one is creating means moving away from participant observation - based on the supremacy of observation over participation where the researcher had to cultivate rapport not friendships, show compassion not sympathy, seek understanding not identification (Tedlock, 2000: 457) - towards the observation of participation. Here it is not the level of immersion that is important but the "competence of introspection and ability to reflect on experience' (Ellen, 1984: 31). The question of whether the researcher can adequately listen and observe is reformulated into the question of whether the researcher can perform competently. In this sense, fieldwork is a time of personal growth for it is an intense educational experience. Learning how to perform competently in different social spheres necessitates sensitivity to your context, and an ability to respond accordingly: a researcher must wear many different hats at different times, as well as be able to build sincere and informative interpersonal relationships with a range of individuals differentiated by gender, race, ethnicity and class.

To be able to engage competently with social actors (whether government bureaucrats, private sector managers, smallholders or slum dwellers) a researcher must be able to display an adequate understanding of their lifeworld and the discourses they use. In offices this might mean understanding the acronyms and buzzwords used by employees, locating political and strategic interests and relating these to broader academic and theoretical arguments. In fields and on the shop floor it might mean understanding a different type of diction, learning about different social practices and conventions, and locating these within broader discourses and arguments (usually formulated within elite spaces in urban areas). Moving between such spheres might bring into relief a tension between how theory and development policy conceptualises the lifeworld of social actors, and the interpretations and folk wisdom of social actors themselves. Such a tension is a good starting point for the iteration of theory and data, using the most appropriate tools from the full spectrum of social science research methods.

\section{Acknowledgements}

I would like to thank the Economic and Social Research Council, UK, for funding the Ph.D. thesis from which this article draws. I must also thank Wendy Olsen for the comments and encouragement, Teresa Gowan for introducing me to the extended case method, Jan Kees van Donge for his encouragement to use ethnography, and Alessandro Conticini and Rita Santos, colleagues at the Institute for Development Policy and Management, University of Manchester, whose theses inspired the main argument of this article. Any inaccuracies presented here are solely my responsibility.

\section{Notes}

1. For an urban-based framework (Moser, 1998).

2. For example, clustering the strategies into the categories commonly associated with the study of total household income - farm, non-farm and off-farm (Ellis, 2000: 11-12) - would appear to be a useful first step. Such a classification could then be altered to better reflect the significance of particular livelihood strategies at the local level. For example, the strategy 
of regular wage employment (whether farm based or not) could be separated out of the off-farm grouping to form a further category. Permanent work of this nature (receiving a regular monthly wage) is fundamentally different from the two other activities in this group (temporary piecework paid in cash or in kind, and the gathering of natural resources).

\section{References}

Allen, T. 1998: 'Informal sectors' to 'real economies': Changing conceptions of Africa's hidden livelihoods, Contemporary Politics 4(4), 357-73.

Andersson, J.A. 2001: Re-interpreting the rural-urban connection: Migration practices and socio-cultural dispositions of Buhera workers in Harare, Africa 71(7), 82-112.

-2006: Informal moves, informal markets: International migrants and traders from Mzimba district, Malawi, African Affairs 105/420, 375-97.

Archer, M., Bhaskar R., Collier A., Lawson T. and Norrie A. 1998: Critical realism: Essential readings. Routledge.

Ashley, C. and Carney, D. 1999: Sustainable livelihoods: Lessons from early experience. DfID.

Baert, P. 1998: Social theory in the twentieth century. Polity Press.

Duflo, E. and Banerjee, A. 2008: The experimental approach to development economics. CEPR working paper No. DP7037, Centre for Economic Policy and Research, London.

Beall, J. 2002: Living in the present, investing in the future - housing security among the poor. In Rakodi C. and Lloyd-Jones, T. editors, Urban livelihoods: A people-centred approach to reducing poverty. Earthscan Publications Ltd, 71-87.

Bernstein, H. 2005: Development studies and the marxists. In U. Kothari, editor, A radical history of development studies. Zed Books, 111-37.

Bhaskar, R. 1978: A realist theory of science. Harvester Press.

1979: Philosophy and the human sciences. Harvester Press.

1989: The possibility of naturalism: a philosophical critique of the contemporary human sciences. Harvester Wheatsheaf.

Booth, D. 2001: Towards a better combination of the quantitative and the qualitative. In Kanbur R., editor, Q-squared: A commentary on qualitative and quantitative poverty appraisal, Working Paper No. 105, Cornell University Department of Applied Economics and Management.

Burawoy, M. 1991: Ethnography unbound: Power and resistance in the modern metropolis. University of California Press.
Burawoy, M.1998: The extended case method. Sociological Theory 16(1), 4-33.

2000: Global ethnography: Forces, connections, and imaginations in a postmodern world. University of California Press.

2003: Revisits: An outline of a theory of reflexive ethnography, American Sociological Review 68(5), 645-79.

Carney, D. editor. 1999: Sustainable rural livelihoods: What contribution can we make? DfID.

Chambers, R. 1989: Vulnerability, coping and policy. IDS Bulletin 20, No. 2, 1-7.

2001: Qualitative approaches: self criticism and what can be gained from quantitative approaches. In Kanbur R., editor, Q-squared: A commentary on qualitative and quantitative poverty appraisal, Working Paper No. 105, Cornell University Department of Applied Economics and Management.

_2007: Who counts? The quiet revolution of participation and numbers. IDSWorking Paper 296, Institute of Development Studies (IDS).

Chambers, R. and Conway, G.R. 1992: Sustainable rural livelihoods: practical concepts for the 21st century. Discussion Paper 296, Institute of Development Studies, Brighton, UK.

Clark, J. and Carney, D. 2008: Sustainable livelihoods approaches - what have we learnt? ESRC Research seminar, Institute of Development Studies, University of Brighton, Sussex, UK, October 2008.

Conticini, A. 2004: We are the kings: The children of Dhaka's streets. Unpublished Ph.D., University of Manchester, Manchester.

Danermark, B., Ekstrom, M., Jakobsen, L. and Karlson, J.C. 2002: Explaining society: An introduction to critical realism in the social sciences. Routledge.

Davis, P. 2006: Poverty in time: Exploring poverty dynamics from life history interviews in Bangladesh, CPRC Working Paper No. 69. Chronic Poverty Research Centre, University of Manchester, UK.

Denzin, N.K. and Lincoln, Y.S. editors. 2000: Handbook of qualitative research. Sage Publications.

Denzin, N.K., 2004: Explaining society: Critical realism in the social sciences. Contemporary Sociology $-a$ Journal of Reviews 33(2), 249-50.

de Waal, A. 1989: Famine that kills: Darfur, Sudan, 1984-1985. Oxford University Press.

Department for International Development (DfID). 2000: Sustainable livelihoods - current thinking and practice. Department for International Development.

Department for International Development (DfID). 2001: Proceedings from forum on operationalizing participatory ways of applying sustainable livelihoods approaches. Department for International Development. 
Dreze, J. and Sen, A. 1991: Hunger and public action. Oxford University Press.

Ellen, R.F. 1984:. Ethnographic research: A general guide to conduct. Academic Press.

Ellis, F. 2000: Rural livelihoods and diversity in developing countries. Oxford University Press.

Fairhead, J. and Leach, M. 1996: Misreading the African landscape. Cambridge University Press.

Ferguson, J. and Gupta, A. 1997: Anthropological locations: Boundaries and grounds of a field science. University of California Press.

Ferguson, J. 1990: The anti-politics machine: 'Development', depoliticization, and bureaucratic power in Lesotho. Cambridge University Press.

Francis, E. 2000: Making a living: Changing livelihoods in rural Africa. Routledge.

Francis, E. 2002: Rural livelihoods, institutions and vulnerability in North West Province, South Africa, Journal of Southern African Studies, 28, 531-50.

Giddens, A. 1984: The constitution of society: An outline of the theory of structuration. Polity Press.

Glaser, B.G. and Strauss A.L. 1967: The discovery of grounded theory: Strategies for qualitative research. Aldine de Gruyter.

Gluckman, M. 1941: Economy of the central barotse plain. The Rhodes-Livingstone Institute.

Green, M. and Hulme, D. 2005: From correlates and characteristics to causes: Thinking about poverty from a chronic poverty perspective, World Development 33(6), 867-80.

Guba, E.G. and Lincoln, Y.S. 1994: Competing paradigms in quantitative research. In Denzin N. and Lincoln, S.Y., editors, The landscape of qualitative research. Sage Publications Ltd, 105-17.

Haggblade, S., Hazell, P. and Reardon, T. 2007: Transforming the rural nonfarm economy: Opportunities and threats in the developing world. Johns Hopkins University Press.

Hammersley, M. 2004: Towards a usable past for qualitative research. International Journal of Social Research Methodology 7(1), 19-27.

Harriss, J. 2002: The case for cross-disciplinary approaches in international development, World Development 30(3), 487-96.

Harriss, J. and Renzio, P.D. 1997: Missing link or analytically missing? The concept of social capital, Journal of International Development 9(7), 919-37.

Hart, K. 1973: Informal income opportunities and urban employment in Ghana, Journal of Modern African Studies 11(1), 61-89.

Hulme, D. and Toye, J. (2006) The case for cross disciplinary social science research on poverty, inequality and the quality of life, Journal of Development Studies, 42, 1085-107.

Huntingdon, S. 1968: Political order in changing societies. Yale University Press.
Hussein, K. 2002: Livelihoods approaches compared: $A$ multi-agency review of current practice. DfID.

Kanbur, R. editor 2001: Q-squared: A commentary on qualitative and quantitative poverty appraisal. Working Paper No. 105, Cornell University Department of Applied Economics and Management.

Kothari, U. editor. 2005: A radical history of development studies. Zed Books.

Long, N. 1968: Social change and the individual: A study of the social and religious responses to innovation in a Zambian rural community. Published for the Institute for Social Research, University of Zambia, Manchester University Press.

- 2001: Development sociology: Actor perspectives. Routledge.

Maqueen, D. 2001: Measurement malaise - is the SL approach inoperable? Natural Resources Institute.

Maxwell, S. 1999: The meaning and measurement of poverty, ODI Poverty Briefing No. 3, Overseas Development Institute, London.

Merton, R. 1967: On sociological theories of the middlerange. In Merton, R., editor, On theoretical sociology: Five essays old and new, Free Press, 39-72.

Miller, R.L. 2000: Researching life stories and family histories. Sage Publications.

Moser, C.O.N. 1998: The asset vulnerability framework: Reassessing urban poverty re-duction strategies, World Development 26(1), 1-20.

Murray, C. 2000: Changing livelihoods: The free state 1990s, African Studies 59, 115-42.

2002: Livelihoods research: Transcending boundaries of time and space, Journal of Southern African Studies 28(3): 489-509.

O'Laughlin, B. 2002: Proletarianisation, agency and changing rural livelihoods: Forced labour and resistance in colonial Mozambique, Journal of Southern African Studies 28, 511-30.

Olsen, W. and Morgan, J. 2005: A critical epistemology of analytical statistics: addressing the sceptical realist, Journal for the Theory of Social Behaviour 35(3), 255-84.

Parsons, T. 1964: Evolutionary universals in society, American Sociological Review 29, 339-57.

Prowse, M. (2007) Burley Tobacco, Food Security and Vulnerability:The Changing Nature of Rural Livelihoods in the Central Region of Malawi, unpublished Ph.D. thesis, University of Manchester, UK.

Pawson, R. 2009: Middle range theory and program theory evaluation: from provenance to practice. In Vaessen, J. and Leeuw, F.L., editors, Mind the gap: Perspectives on policy evaluation and the social sciences. Transaction Publishers, 171-202.

Popper, K.R.S. 1992: The logic of scientific discovery. Routledge. 
Pretty, J. 1999: Capital assets and natural resource improvements: Linkages and new challenges. Centre for Environment and Society, University of Essex.

Prowse, M. 2009: Becoming a bwana and burley tobacco in the central region of Malawi, Journal of Modern African Studies.47, 575-602.

Punch, M. 1994: Politics and ethics in qualitative research. In Denzin, N. and Lincoln, Y., editors, Handbook of qualitative research. SAGE Publications, 83-95.

Rakodi, C. 2002: A livelihoods approach: Conceptual issues and definitions. In Rakodi, C. and LloydJones, T., editors, Urban livelihoods: A people-centred approach to reducing poverty. Earthscan Publications, 3-22.

Rao, V. 2001: Potters and slums: two qualitative/ quantitative projects in India. In Kanbur, R., editor, Q-squared: A commentary on qualitative and quantitative poverty appraisal, Working Paper No. 105, Cornell University, Department of Applied Economics and Management.

Ravallion, M. 2009: Evaluation in the practice of development, The World Bank Research Observer 24(1), 29-53.

Reardon, T. 1997: Using evidence of household income diversification to inform study of the rural nonfarm market in Africa, World Development 25(5), 735-47.

Redclift, M. 1987: Sustainable development: Exploring the contradictions. Methuen.

Rodrik, Dani. 2009: The new development economics: We shall experiment, but how shall we learn? In Cohen, J. and Easterly, W., editors, What works in development? Thinking big and thinking small. Brookings Institution Press, 24-47.

Santos, R.C.L.F.D. 2005: Development and sustainability of information systems for public budget transparency: A case study from Brazil using a new institutional approach. Unpublished Ph.D. thesis, University of Manchester, Manchester.

Schwandt, T.A. 2000: Three epistemological stances for qualitative inquiry: Interpretivism, hermeneutics, and social constructionism. In Denzin, N.K. and Lincoln, Y.S., editors, Handbook of qualitative research. SAGE Publications, 189-213.

Scoones I. (1998) Sustainable rural livelihoods: A framework for analysis. IDS Discussion Paper 72, Institute of Development Studies, University of Sussex.

Sen, A. 1981: Poverty and famines: An essay on entitlement and deprivation. Clarendon Press.

Steinmetz, G. 1998: Critical realism and historical sociology. A review article, Comparative Studies in Society and History 40(1), 170-86.
Steinmetz, G. 2004: Odious comparisons: Incommensurability, the case study, and 'small N's' in sociology, Sociological Theory 22(3), 371-400.

Steinmetz, G. and Chae O. B. 2002: Sociology in an era of fragmentation: From the sociology of knowledge to the philosophy of science and back again. Sociological Quarterly 43(Winter): 11-37.

Stewart, F. 1985: Planning to meet basic needs. Macmillan.

Streeten, P., Burki, S.J., M. ul Haq, Hicks, N. and Stewart, F. 1982: First things first: Meeting basic human needs in the developing countries. Published for the World Bank by Oxford University Press.

Tedlock, B. 2000: Ethnography and ethnographic representation. In Denzin, N.K. and Lincoln, Y.S., editors, Handbook of qualitative research. SAGE, 455-86.

Thin, N. 2000: Characteristics of DFID-funded projects. SCOPE paper No. 12. Social Development Department, Department for International Development, London.

Thomas, W.I. and Znaniecki F.W. 1927: The Polish peasant in Europe and America. A. A. Knopf.

Toner, A.L. 2003: Knowing poverty: critical reflections on participatory research and policy, Journal of Development Studies 40(1), 183-85.

Turner, V.W. 1957: Schism and continuity in an African society: A study of Ndembu village life. Published on behalf of the Rhodes-Livingstone Institute by Manchester University Press.

van Velsen, J. 1964: The politics of kinship: A study in social manipulation among the Lakeside Tonga of Nyasaland. Manchester University Press.

van Velsen, J. 1967: The extended-case method and situational analysis. In Epstein, A.L., editor, The Craft of Social Anthropology. Tavistock, 129-52.

Vidich, A.J. and Lyman, S.M. 2000: Qualitative methods: their history in sociology and anthropology. In Denzin, N.K. and Lincoln, Y.S., editors, Handbook of qualitative research. SAGE, 37-84.

Willis, P. and Trondman, M. 2000: Manifesto for ethnography, Ethnography 1(1), 5-16.

Wilson, G. 1941: An essay on the economics of detribalization in Northern Rhodesia. By Godfrey Wilson. The Rhodes-Livingstone Institute.

Wood, G. 2003: Staying secure, staying poor: The 'Faustian Bargain', World Development 31(3), 455-71.

Wood, G. and Solway, S. 2000: Securing livelihoods in Dhaka slums, Journal of International Development, $12,669-88$.

Woodhouse, P. 1998: People as informants. In Thomas, A., Chataway, J. and Wuyts, M., editors, Finding out fast: investigative skills for policy and development. Oxford University Press, 127-46. 
Woolcock, M. 2001: The place of social capital in understanding social and economic outcomes, Canadian Journal of Policy Research 2, 11-17.

2009: Towards a plurality of methods in project avaluation: A contextualised approach to understand- ing impact trajectories and efficacy. Working Paper 73. Brooks World Poverty Institute, University of Manchester, UK.

World Bank. 2000: World development report 2000/1. World Bank. 